\section{SOVIET WAR-TIME SURGERY}

W

HEN four British surgeons flew to the U.S.S.R. and stayed there for three weeks, they were given a great welcome and were taken not only to medical institutions in Moscow but also up the $\operatorname{line}$ so far forward as Vyazma to study the field and mobile hospitals. They learned that the Soviet surgeons have no new fundamental principles to teach us and do not need to learn any from us; their principles are the same as ours and differ only in the details of their application'. But young Russian surgeons would benefit from a study of our best hospital practice and our young surgeons would learn much from the Russian clinics. The methods of some Russian surgeons are notable. Prof. Yudin, for example, apart from his remarkable operation for replacement of the obstructed œsophagus by the jejunum, differs somewhat in his use of the skintight plaster for the treatment of war wounds. This method has been attributed to the Soviet surgeon Pirogoff, who, when he was short of splints in the Crimean War, cut out sailcloth to the patterns required and dipped these in plaster. This closedplaster method was developed by Trueta in the Spanish Civil War. The closed-plaster method has been also attributed to Trueta himself, to WinnettOrr in the United States, to Mettita in Italy and to Ollier in France.

While neither Soviet nor European anæsthetic practice is so good as it is in Great Britain or the United States, the Soviet system of blood transfusion was found by our visiting surgeons to be beyond criticism and it is done on a huge scale ${ }^{3}$. In one Moscow institution alone 500-800 donors are bled every day and 90 per cent of them are women. Donors get extra rations and also pay, but fourfifths of the money is returned for war purposes. There is never any lack of blood; it is flown to the front and has even been flown to Soviet wounded behind the German lines.

Another valuable feature of the Soviet Army Medical Service is the practice of sorting out all types of case in clearing stations five miles behind the firing line. This is done by an experienced surgeon and the cases are then sent to specialist hospitals, where they are treated by specialists in the kind of injury from which they are suffering. But before they are sent away they receive immediate treatment from young members of surgical teams, who are trained to give the treatment which the senior specialists expect them to have had. The clearing stations immediately behind the front are well equipped and each has a series of special units complete in itself. Perhaps this system-and the tough Russian constitution-has helped the Russians to return 70 per cent of their wounded to the firing line. Some of its features were shown in a film given to the Royal College of Surgeons last October ${ }^{4}$. This film was made two years ago. It showed the rescue of wounded by sledge, the method of giving each patient a bath, a shave and a general clean-up, and some of the methods of rehabilitation of function after injuries. It also showed some of the wards, which are less formal than those in British military and other hospitals.

The Russian military nurse awoke the admiration of the visiting surgeons. She not only does her job very well but also helps to build the hospital in which. she works, cutting down trees, squaring up timber, making the frames of windows and doors and digging foundations. The British surgeons were impressed by her skill in camouflage. On one occasion they stopped in what appeared to be a forest; it turned out to be the entrance to a hospital containing a thousand beds. Some of the buildings had been built round the trees, which projected through the roofs. One is reminded of a certain medical unit at Makina, Basra, during the War of 1914-18, at which the reed huts were built round the palm trees in this way; the palm trunks made useful wardrobes.

The medical service of the U.S.S.R. is becoming a woman's service, 90 per cent of the doctors now under training being women. They take a five-year course, while a nurse's course has been reduced from three years to two.

The British surgeons were also much impressed by the emergency medical service in Moscow, the organization of which recalls the organization of the National Fire Service in Britain. Moscow is divided into areas, a map of which enables telephone operators detailed for night duty to send, within a few minutes, in response to a call for medical help, a well-equipped ambulance, with a doctor, a nurse and an orderly, to the house requiring them. The central operator uses a device which illuminates on the map of the city the street from which the call comes and also the nearest ambulance depot, with which she then communicates. There would appear to be no reason why cities in Britain should not be supplied with this valuable service.

Soviet military ophthalmology has recently been described by Prof. Kolen, head of the Novosibirsk Eye Clinic ${ }^{5}$. Evidently it is obtaining good results in its treatment of the dangerous and distressing injuries which involve not only the all-important eye, but also the neighbouring organs and the face in general. Wound-healing by the transplantation of tissues is also widely practised ${ }^{6}$. Dead tissues treated with chloraclyde are used as an aid in healing up fresh and granulating wounds, and regeneration is stimulated with emulsions of embryonal tissue obtained from guinea pigs and used in castor oil as a liquid base. G. LAPAGE.

1 Lancet, 198 (Aug. 14, 1943).

2 Lancet, 485 (Oct. 16, 1943).

Brit. Med. J., 208 (Aug. 14, 1943).

- Lancet, 487 (Oct. 16, 1943).

5 Lancet, 804 (June 26, 1943).

- Science, 97, 162 (1943).

\section{UTILIZATION OF BAMBOOS IN INDIA}

$A$ $\mathrm{S}$ is well known, in tropical and subtropical countries where the bamboo in one or more of its many genera and species flourishes, man, as represented by the local population, has over very long periods of time made extensive use of it-in fact, from house construction down to the provision of the woman's household utensils and even part of the clothing. The bamboo has probably been as serviceable in an all-round fashion to man as any other single vegetable product. It is of interest, therefore, to follow its more modern uses by civilized man who has long discarded its former utilitarian ones.

In a Utilisation brochure issued by the Forest Research Institute, Dehra Dun (Indian F'or. Rec., For. Res. Pub., Dehra Dun, 1943), V. D. Limaye describes some investigations into "Bamboo Nails, their Manufacture and Holding Power'. The investigation 
was commenced owing to the fact that wire nails had become very difficult to obtain in India, while the demand for packing cases, not least for army requirements, had increased enormously. Experiments were carried out to see how bamboo nails compared in holding power and other qualities with wire nails. The results of the tests are given; and sketches of largescale production of bamboo nails are included and the process of manufacture described.

Truly India is a fortunate country when her carefully supervised forest wealth enables her to confront one difficulty after another in times of dire stress through the work of her research officers. "It has been found", says the author, "that glued bamboo nails have a greater holding power than plain iron nails under a steady pull. But when shocks and transportation hazards are met with, their holding power diminishes". A small percentage of iron nails in a packing case is, therefore, necessary, especially for fixing the battens by clinching. It was found by actual tests that if 25 per cent iron nails and 75 per cent bamboo nails are used, a strong and serviceable box results, with a very considerable saving in costs of manufacture.

Another use of the bamboo has been found in the manufacture of pill or ointment boxes. Due to a shortage of metal, various substitutes have had to be used in the construction of containers; thus plywood containers have already been mentioned in NATURE (Ind.For. Leaf. 24 and 26). In Leaflet 39 (1943) Sultan Mohammed discusses the method of making from bamboo small pill and ointment boxes. Details of manufacture are given including some information on suitable coatings and linings. It is said that a fairly competent turner will find no difficulty in making these boxes with the aid of a lathe and ordinary tools. The description is of interest: "A bamboo container consists of a short length of bamboo (according to size of container required) which forms the walls of the body and lid of the container. The top and the bottom are made of thin three plywood and are provided with a locking device so that, if the top becomes loose due to climatic changes, the lid will still be held tight. The container is usually coated or painted, both inside and outside, with the object of retarding the absorption of moisture by sealing the pores of the bamboo, and to give a smooth clean finish."

\section{THE SCIENCE OF TOMATO GROWING}

$\mathrm{T}$

HE Cheshunt Experimental and Research Station has devoted its energies during war-time wholly to the elucidation of problems connected with food crops. Reports of investigations on the tomato occupy most of the twenty-eighth annual report, for 1942, of the Station (from the director, Dr. W. F. Bewley, The Nursery and Market Garden Industries' Development Society, Ltd., Turner's Hill, Cheshunt, Herts, 1943). Trials of the value of muriate of potash as against sulphate of potash resulted in a small, though scarcely significant, increase of crop in favour of the sulphate. No harmful foliage effects were observed when muriate was added, and it would seem that widespread doubts about the suitability of muriate of potash for the indoor tomato crop are now dispelled.

Much research has been devoted to diseases and pests of the tomato. Two varieties, Manx Marvel and Riverside, showed significant resistance to the wilt fungus Verticillium albo-atrum. Tomato stemrot caused by the fungus Didymella lycopersici caused widespread damage in 1942 to plants growing in the greenhouse and in the open. The disease appears to be carried from crop to crop on wire supports and strings, and may be controlled by suitable methods of hygiene. Experiments have also been made with fungicides as soil treatment, or applied as sprays and dusts to the plant, or as a protection of the 'collar', where infection normally occurs in greenhouse tomatoes.

Control of the wireworm pest by trapping with carrot bait gave rather disappointing results, and the elimination of these larvæ still remains one of the outstanding problems of pest control. Other negative results were obtained with sprays containing tartar-emetic and glycerine, advocated in the United States against the red-spider mite, and with potassium iodide solution for the prevention of damage by the root-knot eelworm.

Tomatoes in sand culture exhibited clear-cut symptoms when deprived of boron, manganese and magnesium. Omission of boron and magnesium from the culture solution produced marked stunting, and boron deficiency caused a leaf scorch similar to that sometimes associated with acute potassium starva. tion. Lack of magnesium induced a withering of the tips of leaflets, whereas the absence of manganese brought about a mottling of the leaf with uniform yellow specks. The report contains details of these and other investigations in the form of short papers by the authors of each subject for research.

\section{HYDROGEN EXCHANGE REACTIONS}

TN two papers (J. Chem. Soc., 361, 367; J943) H. V. A. Briscoe and co-workers describe the results of experiments on the interchange of hydrogen isotopes with complex salts, ammines of cobalt, and platinum and palladium being studied. The hydrogen of $\left[\mathrm{Co}\left(\mathrm{NH}_{3}\right)_{6}\right] \mathrm{Cl}_{3}$ and [Co $\left.\mathrm{en}_{3}\right] \mathrm{Cl}_{3}$ (en = ethylenediamine) undergoes isotope exchange with heavy water $\left(D_{2} O\right)$ in solutions, the interchange following a unimolecular law with a rate inversely proportional to the hydrogen ion concentration but practically independent of the ammine concentration or its deuterium content. The exchange mechanism is explained by assuming that the metal ammine group $M-\mathrm{NH}_{3}$ can ionize as an acid : $M-\mathrm{NH}_{3}=$ $M-\mathrm{NH}_{2}^{\prime}+\mathrm{H} \cdot$, this being parallel to the ionization of aquo-ammines, which form hydroxo-ammines. There is some evidence that the case of acid dissociation runs parallel with the stability of the ammines. The reaction mechanism is very fully discussed in the papers on the basis of the kinetics.

The rate of interchange of hydrogen isotopes with ammines of different metals decreases in the order $\mathrm{Co}>\mathrm{Pt}>\mathrm{Pd}$ and runs parallel to the complex ions. In the case of $\left[\mathrm{Pd}\left(\mathrm{NH}_{3}\right)_{4}\right] \mathrm{Cl}_{2}$ the interchange mechanism is complex; in addition to the acid dissociation mechanism, it reacts in acid solution by reversible dissociation of ammonia from the complex. This points to a continuous gradation between the two extreme types of ammonia complexes represented by the stable metal ammines of the $\left[\mathrm{Co}\left(\mathrm{NH}_{3}\right)_{6}\right] \mathrm{Cl}_{3}$ 